\title{
Reproducibility of Growth Hormone Stimulation Tests (Arginine and Insulin), Insulin-like Growth Factor (IGF)- I and IGF-Binding Protein-3 Measurements
}

\author{
Yukihiro Hasegawa, Tomonobu Hasegawa, Shinobu Kotoh and Yutaka Tsuchiya \\ Division of Endocrinology and Metabolism, Tokyo Metropolitan Kiyose Children's Hospital, \\ Tokyo, Japan
}

Abstract. Recently there have been some data suggesting that the results of GH stimulation tests are not reproducible. We studied here the reproducibility of $\mathrm{GH}$ stimulation tests (arginine and insulin) and compared it with the reproducibility of serum IGF-I and IGFBP-3 measurements. The interdaily variation of traditional GH tests can be higher than that of IGF-I and IGFBP-3 measurements. We should not over-rely upon traditional GH stimulation tests to diagnose GH insufficiency.

Key words: reproducibility, GH stimulation tests, arginine and insulin tests, IGF-I, IGFBP-3

Recently there have been some data suggesting that the results of $\mathrm{GH}$ stimulation tests, which have been used in the diagnosis of GH insufficiency, are not reproducible $[1,2]$. We studied here the reproducibility of $\mathrm{GH}$ stimulation tests (arginine and insulin) and compared it with the reproducibility of serum IGF-I and IGFBP-3 measurements.

\section{Subjects}

The subjects were 11 control children (CC: height $>$ mean -2 SD), 13 normal short children (NS: height $<$ mean -2 SD), and 11 patients with growth hormone insufficiency (GHI). In NS, at least one of the $\mathrm{GH}$ peaks of the $\mathrm{GH}$ stimulation tests was over $10 \mathrm{ng} / \mathrm{ml}$.

Correspondence: Dr. Yukihiro Hasegawa, Chief, Division of Endocrinology and Metabolism, Tokyo Metropolitan Kiyose Children's Hospital, 1-3-1, Umezono, Kiyose, Tokyo 204 Japan
In patients with $\mathrm{GHI}$, all the $\mathrm{GH}$ peaks were less than $10 \mathrm{ng} / \mathrm{ml}$.

The 15 subjects ( $2 \mathrm{CC}$ and $13 \mathrm{NS}$ ) for checking the reproducibility of the $\mathrm{GH}$ stimulation tests were all prepubertal and their height SD scores were $-3.13 \pm 1.17$ SD $(-1.35$ $\sim-5.52 \mathrm{SD})$. The 28 subjects (9 CC, $8 \mathrm{NS}$ and $11 \mathrm{GHI}$ ) for checking the reproducibility of IGF-I and IGFBP-3 were prepubertal or pubertal and their height $\mathrm{SD}$ scores ranged from mean $+1.0 \mathrm{SD}$ to mean $-5.6 \mathrm{SD}$.

\section{Method}

(1) GH was measured by IRMA (Eiken Kit).

(2) IGF-I was measured with RIA after acid ethanol extraction [3].

(3) IGFBP-3 was measured with Ranke and Blum's RIA kit [4-6], with a few modifications.

(4) Arginine and insulin tests were done as 
Table 1. Arginine and insulin test (Insulin is injected $2.5 \mathrm{hr}$ after starting arginine infusion)

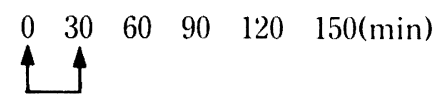

Arg. infusion

$0.5 \mathrm{~g} / \mathrm{kg}$

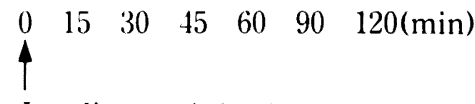

Insulin one injection

$0.11 \% \mathrm{~kg}$

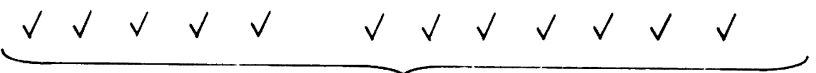

blood sampling for $\mathrm{GH}$

follows (Table 1):

Arginine was infused $(0.5 \mathrm{~g} / \mathrm{kg}$ for $30 \mathrm{~min})$, followed by insulin injection $(0.1 \mathrm{U} / \mathrm{kg}$ one IV injection) two and half hours after starting arginine infusion. Blood was taken $0,30,60$, $90,120,150 \mathrm{~min}$ after arginine infusion and 0 , $15,30,45,60,90,120 \mathrm{~min}$ after insulin injection.

(5) Reproducibility of GH stimulation tests was analysed within an interval of two years. Four out of 15 subjects were checked twice within an interval of two months ( $O$ in Figure 1 and 2). Reproducibility of IGF-I and IGFBP-3 for prepubertal patients was checked at least three times within an interval of less than 6 months (usually three months), and for pubertal patients it was checked at least three times within an interval of one month.

(6) False positive ratio was arbitrarily determined on the presumption that $\mathrm{GH}$ secretion status was normal if any one of the $\mathrm{GH}$ peaks among GH stimulation tests was over $10 \mathrm{ng} /$ $\mathrm{ml}$.

\section{Results}

(1) The ratios of $\mathrm{GH}$ peaks in the first arginine and insulin tests to $\mathrm{GH}$ peaks in the second tests varied to a great extent (Figure 1 and 2). Twelve out of 56 showed false positive results,

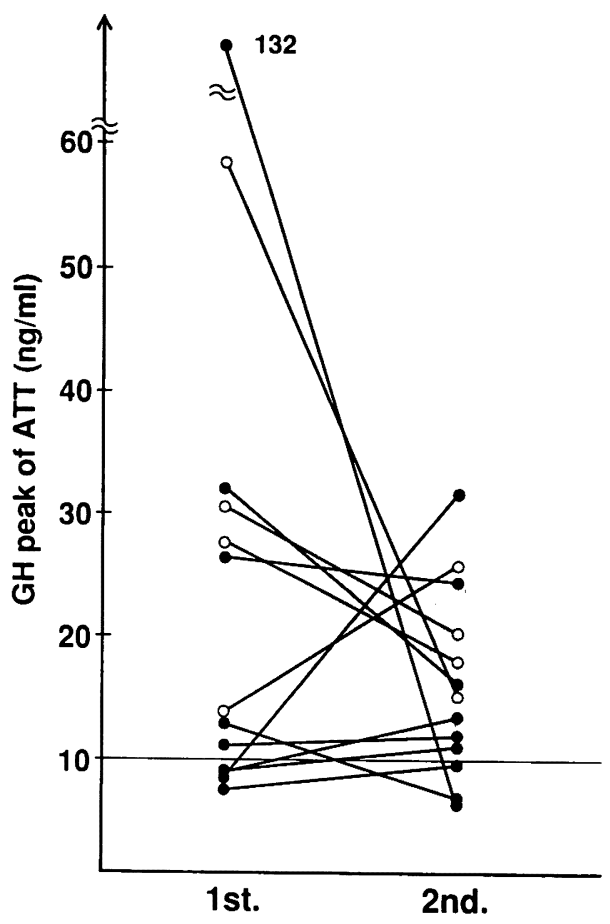

Fig 1. GH peaks of two arginine tests (an interval of $O$ and $\bullet$ is $<2$ months and $<2$ years, respectively).

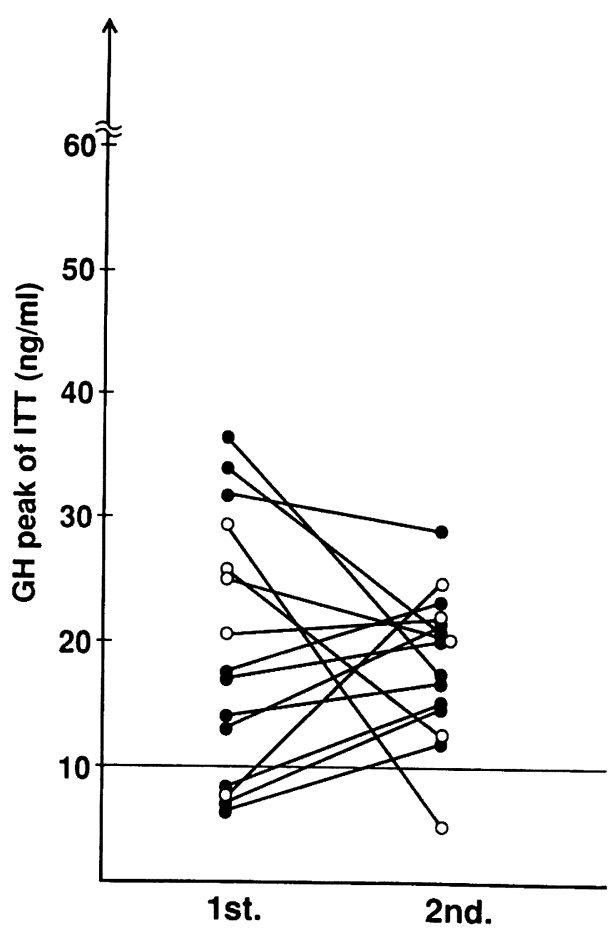

Fig 2. GH peaks of two insulin tests (an interval of $O$ and $\bullet$ is $<2$ months and $<2$ years, respectively). 
Reproducibility of GH Stimulation Tests

Table 2. False positive ratios of GH stimulation tests in each height group or IGF-I group

\begin{tabular}{|c|c|c|}
\hline \multirow{3}{*}{ height } & $<$ mean-4SD & $2 / 16(12.5 \%)$ \\
\cline { 2 - 3 } & $<$ mean-2SD & $10 / 40(25 \%)$ \\
\cline { 2 - 3 } & $>$ mean-2SD & $2 / 6(33 \%)$ \\
\hline \multirow{2}{*}{ IGF-I } & $<5$ th percentile & $3 / 12(25 \%)$ \\
\cline { 2 - 3 } & $>5$ th percentile & $9 / 44(20 \%)$ \\
\hline
\end{tabular}

if based on the lower $\mathrm{GH}$ peaks. When we divided the subjects into subgroups with heights under mean $-2 \mathrm{SD},-4 \mathrm{SD}$, and over mean $-2 \mathrm{SD}$, each false positive ratio is shown in Table 2. Similarly, false positive ratios for each low and normal IGF-I are shown in Table 2. There was no tendency that the higher the heights, the lower the false positive ratios were. Also there was no statistical difference in false positive ratio between subjects with low IGF-I $(<5$ th percentile of normal children [3]) and normal IGF-I ( $>5$ th percentile of normal children [3]).

(2) Interdaily variation of IGF-I (percentage of each SD to mean) was $22.0 \pm 13.9 \% \quad(n=28$, range, $2.5-45.9 \%$ ). Mean IGF-I levels of each subject for this study ranged from 21 to $573 \mathrm{ng} / \mathrm{ml}$.

(3) Interdaily variation of IGFBP-3 (percentage of each SD to mean) was $10.8 \pm 6.7 \%(n=$ 27, range, $0-25.4 \%$ ). Mean IGFBP-3 levels of each subject for this study ranged from 0.21 to $4.44 \mathrm{mg} / \mathrm{L}$.

\section{Discussion}

It has been reported that IGF-I and IGFBP-3 do not show much daily variation $[7,8]$. Our data about IGF-I and IGFBP-3 interdaily variation confirmed previous reports $[7,8]$. The interdaily variations of these two parameters were less than that of our GH stimulation tests at least in some patients, suggesting that these two values were more stable than results of $\mathrm{GH}$ stimulation tests.

There have been two reports that in some patients with short stature, GH stimulation tests were not reproducible $[1,2]$. We confirmed the limitation of $\mathrm{GH}$ stimulation test in terms of reproduciblity. Furthermore, the results of the false positive ratios of $\mathrm{GH}$ stimulation tests in each height group and IGF-I level group suggested that these false positive results might not reflect heights or IGF-I levels.

Taken together, we should not over-rely upon the results of $\mathrm{GH}$ stimulation tests, which have been used in the diagnosis of $\mathrm{GH}$ insufficiency for many years.

\section{References}

1. Donaldson DL, Pan F, Hollowell JG, Stevenson JL, Gifford RA, Moore WV. Reliability of stimulated and spontaneous GH levels for identifying the child with low GH secretion. J Clin Endocrinol Metab 1991; 72:647-52.

2. Zadik Z, Chalew SA, Kowarski AA. Reproducibility of growth hormone testing procedures: Quantitative comparison between 24-hour integrated concentration and pharmacological stimulation. J Clin Endocrinol Metab 1990; 71: 1127-30.

3. Hasegawa Y, Hasegawa T, Kotoh S, Tsuchiya $\mathrm{Y}$, Harada $\mathrm{A}$, Horie $\mathrm{H}$, et al. The clinical utility of IGF-I in the diagnosis of growth hormone deficiency. Clinical Endocrinology (in Japanese) 1992; 40: 1107-10.

4. Hasegawa Y, Hasegawa T, Kotoh S, Tsuchiya Y, Yokoyama, Ohyama Y, et al. Usefulness and limitation of measurement of IGFBP-3 for diagnosis of growth hormone deficiency. Endocrinol Japon 1992; 39(6): 585-91.

5. Hasegawa Y, Hasegawa T, Kotoh S, Tsuchiya Y, Yokoyama, Ohyama Y, et al. Clinical utility of IGFBP-3 measurement in the diagnosis of GHD. Clinical Endocrinology (in Japanese) 1992; 40: 213-7.

6. Toyama $M$, Hasegawa $Y$, Hasegawa $T$, Tsuchiya Y, Kurimoto F. Basic study about IGFBP-3 radioimmunoassay. Clinical Endocrinology (in Japanese) 1992; 40: 


\section{HASEGAWA et al.}

1085-90.

7. Daughaday W, Rotwein P. Insulin-like growth factors I and II-Peptides, messenger ribonucleic acid and gene structures, serum and tissue concentrations. Endo Reviews 1989; 10: 68-91.
8. Blum WF, Ranke MB. Plasma IGFBP-3 levels as clinical indicators. In: Spencer EM, editors. Modern concepts of insulinlike growth factors, New York, Amsterdam, London and Tokyo: Elsevier, 1991: 381-93. 